\title{
Professional networking by gender: A case study on LinkedIn contacts for a professor in science
}

\author{
Anders Lindh Olsson ${ }^{1, \S}$, Markus Snellman ${ }^{1, \S}$, \\ Knut Deppert ${ }^{1, *}$ and Inger Lövkrona ${ }^{1}$ \\ ${ }^{1}$ Lund University, Lund, Sweden \\ $\S$ These two authors contributed equally to this work \\ *knut.deppert@ftf.lth.se
}

September 2020

\begin{abstract}
In this study, we used data from LinkedIn networks to gain insight in how different groups network in terms of network size and gender composition among men and women. We have gathered categorical data from 751 LinkedIn networks to quantitatively analyze networking tendencies and network gender compositions in the categories gender, age, sector of work, field of work, level of education and area of residence. We have also determined networking "savviness" as a quantitative measure of social networking for comparing groups in the categories. The observations made regarding networking behavior among female and male LinkedIn users include that women on average had more female contacts than men in all categories. Female networks working in a non-technical field were found to have the most gender equal networks of all groups with an average of $42.5 \%$ female contacts. The data show further, that men and women in STEM and the private sector were savvier networkers and that users with a $\mathrm{PhD}$ had fewer female contacts on average than those without a PhD. Further, Scandinavian networks had significantly more female contacts in their networks than networks from other European countries and North America had.
\end{abstract}

Keywords - social networks, social communication, professional networking, gender equality, social media 
Professional networking by gender: A case study on LinkedIn contacts for a professor in science

\section{Introduction}

Networking aims at gaining resources that either improve the professional situation or has a strategic influence on the career. Networking includes behaviors that construct, develop and use informal professional relations with the aim to gain professional resources. It is an important component in self-management of a career (van den Brink \& Benschop, 2014; Schoen, Rost, \& Seidl, 2018; Yang, Chawla, \& Uzzi, 2019). In the literature, it is postulated that the importance of networking is increasing in times of globalization and new technologies demand a much higher degree of flexibility. Organizations and industry try to reach this flexibility by flattening hierarchies, outsourcing and organizational structures that are network-like (Allred, Snow, \& Miles, 1996; King, 2004). Thus, individuals need to adapt. We seem to have a general consensus that individuals today must have a high degree on career self-management for their own professional development in order to stay on or improve their position in their profession (King, 2004; Sturges, Guest, Conway, \& Davey, 2002; Heijde \& Van Der Heijden, 2006).

The majority of studies on the intensity how individuals use networking do not find differences between male and female individuals (Forret \& Dougherty, 2001; Sturges et al., 2002; Wanberg, Kanfer, \& Banas, 2000; Wolff \& Moser, 2006) as well as related to age or education (Gould \& Penley, 1984; Sturges et al., 2002; Wanberg et al., 2000; Wolff \& Moser, 2006). However, networking itself is proven to have different effects regarding to gender. Forret and Dougherty (2004) report a stronger correlation for men between networking and objective career development. Thus, while male and female individuals invest in a similar way in networking the outcome regarding career is different when it comes to gender. This difference has in more recent studies been explained by the gender composition and communication patterns in a network. For instance, when the proportion of women exceeds $15 \%$ in a workplace both men and women benefit from the same network structures (Schoen et al., 2018). Similarly, a study in a highschool context shows that women's centrality in a network, that is a network with a female dominated inner circle, is beneficial for women's future leadership success (Yang et al., 2019).

Traditionally, research on networking is conducted through questionnaires and interviews. With the existence of internet-based networking platforms (social media) we have a new way of investigating networking behavior.

With more than 500 million users globally in 2017, LinkedIn is the dominating professional networking social medium (Darrow, 2017). About $57 \%$ of the users are men and $43 \%$ are women, i.e. more men than women use LinkedIn (Aslam, 2018), in contrast to Facebook and Twitter, which have more female users (Grant, 2017). Like other social media (e.g. Facebook, Twitter, Snapchat), LinkedIn user activities generate large amounts of data that can be used for extensive statistics about different networks. One use of this data lies in studying how professionals network, albeit few groups have so far studied this. In 2011, the LinkedIn analytics team published a gender analysis of LinkedIn users titled "The Gender Divide: Are Men better than Women at Social Networking?" (Nicholson, 2011). In the study, the team defined "networking savvy" as the ratio of one way contacts for female and male contacts to the percentage of female and male contacts in a number of professional occupations. For example, a given profession was said to be female savvy if $30 \%$ of the contacts in the profession (category) were female but had $60 \%$ of all one way contacts in that profession or category.

\section{Materials and methods}

In this study, we have been investigating similarities and differences in how groups of LinkedIn users in different categories tend to network professionally online, in part by extending the methods by Nicholson (2011) to more categories, in part by analyzing the users' network gender compositions in the categories. A general purpose of this study is to contribute to knowledge about networking tendencies for women and men in a few categories. 
Professional networking by gender: A case study on LinkedIn contacts for a professor in science

The underlying data used in the study comes from in total 751 individual LinkedIn networks that have been gathered using the LinkedIn contacts of one LinkedIn user. The study is quantitative and can hopefully lead to observations that can be further studied using qualitative and quantitative methods.

Our strategy to obtain data from LinkedIn networks has been to start from one user's LinkedIn network and use the LinkedIn networks of the contacts in that network. The LinkedIn user whose network was used to collect the data from the LinkedIn networks is referred to as the primary user. The primary user is a middle-aged white male science professor working in Scandinavia, with a sufficiently large number of contacts in order to obtain statistical reliable data. All of the primary user's contacts in his LinkedIn network are the networks that have been analyzed in this study. They are referred to as the networks and their contacts are in turn labeled simply as contacts.

The contacts that make up the networks form the basis for the quantitative analysis of the networks in the study. Assessing the gender of the contacts has allowed us to investigate the gender distribution among the networks. The data has also allowed us to measure "networking savviness" for groups of networks in different categories, which is one approach to quantitatively measure and compare networking between groups. Qualitatively, Nicholson (2011) defines a "savvy networker" as "a professional with a robust network of trusted business contacts who actively works toward creating new career opportunities for themselves and the people in their network". To quantify networking savviness, we use the quantitative approach by Nicholson (2011). The quantitative measure of networking savviness is there defined as the ratio of how large share of contacts one group of networks in a category has to how large that group is in the given category. A group in the category education can for instance be networks of female users where the users have a $\mathrm{PhD}$. We define a savviness value $S$ for a group in a category:

$$
S=\frac{\begin{array}{c}
\% \text { of all contacts in the } \\
\text { category belonging to the group }
\end{array}}{\begin{array}{c}
\text { of all networks in the } \\
\text { category belonging to the group }
\end{array}}
$$

With the definition in Eq 1 we see that a value of $S>1$ for a group means that this group is considered savvier than the other groups in the category. Consequently, a number of $S<1$ means that this group is considered less savvy in the comparison. In the case of $S \approx 1$ (here: $0.95 \leq S \leq 1.05$ for all groups), the groups being compared are considered equally networking savvy.

A LinkedIn page typically displays age, country of residence, job, education etc., but the information available varies from contact to contact; consequently, the size of the datasets (i.e. number of networks) vary in each category. Therefore, we have limited our analysis to the following categories: age, sector of work (public and private), field of work (STEM (Science, Technology, Engineering and Mathematics) and non-STEM occupations), education (PhD and non $\mathrm{PhD}$ ) and area of residence (Scandinavia, other European countries and North America).

The collection of categorical data from the networks could not be automated by scripts and was therefore done by hand. Some categorical data were collected through other services than LinkedIn (for example through publicly available CVs, or from national registers).

LinkedIn does not ask for gender during the registration process. To assess the gender of the network users and their contacts, we used the same methods as LinkedIn does in their analyses (Nicholson, 2011): we determined the gender by name, profile picture and any additional data. A simple counter was coded to assist with the counting of contacts. If a network had more than 500 contacts their network size is listed exactly as 500 contacts by LinkedIn, and we limited the data to networks with less than 500 contacts. Additional exclusion of company profiles, networks of users whose genders could not be determined, and shared profiles lead to a dropout of about 150 networks. This amounted to $15-16 \%$ of the networks among all networks 
Professional networking by gender: A case study on LinkedIn contacts for a professor in science

at the time of data collection and we do not consider the dropout being an issue for the study. The gathering of data was made with each contact's complete anonymity in mind and no data in this study can be associated with a certain person. Names have not been stored in order to anonymize the data. It is impossible to connect the individuals to the results presented in the study. While the primary user may be personally acquainted with his LinkedIn network contacts, we are not aware that any relationship between the authors and these contacts exist.

After segmenting the data from the networks into categorical data, we have analyzed the gender distributions among groups in most categories by constructing frequency plots (histograms) of the data as a function of the percentage of female contacts that make up the networks. Fig 1 serves to depict the general result from the analysis. We have made the assumption that the data is essentially normal distributed and made normal distribution fits to the histograms and simply omitted the frequency plots in all figures but Fig 1 . The corresponding frequency plots to the figures in Result and discussion can be found in supporting information. As Fig 1 shows, this assumption turned out to be representative of the full dataset. Statistical differences in gender composition of networks are assessed between groups by comparing $95 \%$ confidence intervals around the means of the normal distributions.

\section{Results and discussion}

The primary user's entire network consisted of more than 900 networks at the time of data collection. Removing networks of users whose gender could not be determined, company profiles, shared profiles as well as networks with more than 500 contacts resulted in a total of $n$ $=751$ networks, out of which $210(28.0 \%)$ were female and $541(72.0 \%)$ were male. Including the network of the primary user, this yields 752 networks in total which we analyze here.

It has been argued, that women on average have fewer professional network contacts than men (Aldrich, 1989). From our data, see Table 1, it

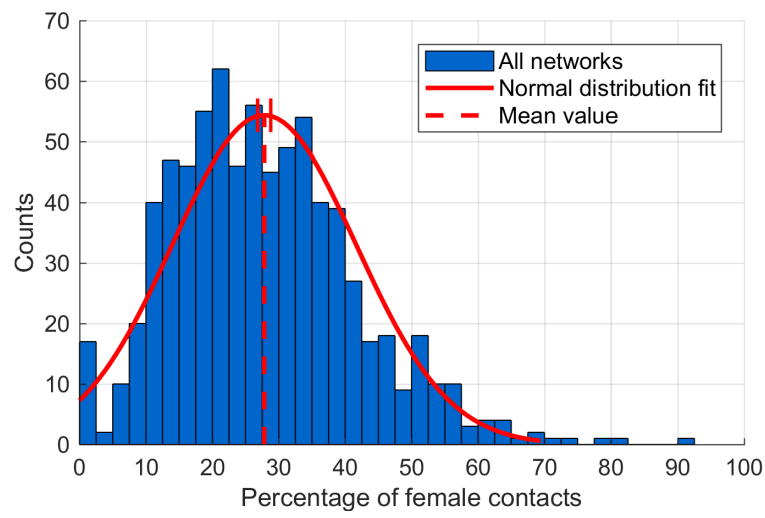

Figure 1 - Distribution of gender compositions of the networks. Normal distribution fit (red) to frequency plot (blue) for all networks $(n=751)$ as a function of percentage of female contacts in the networks.

is obvious that this is true for the 752 networks studied here although the numbers do not differ drastically: here, female networks have 167 contacts on average, while for male networks this number is 180 .

\section{Gender}

Table 1 makes it apparent that there exists a statistical difference in the average gender composition among the female and male networks. Female networks have significantly more female contacts in their networks $(37.8 \%)$ than male networks do (24.2\%), showing that female networks have more balanced gender compositions. Though this result is not surprising if one expects that female LinkedIn users network more with other female users than male LinkedIn users do, the average percentage of female contacts in a female user's network is still far from $50 \%$. This result does not necessarily indicate that LinkedIn networks are generally male dominant (although there are more male users on LinkedIn (Aslam, 2018)); instead the result could originate from similar reasons as to why the primary user's network is biased towards male contacts, be it due to similar field of work or other reasons.

Female and male networks are similarly savvy when it comes to networking. Out of all 
Professional networking by gender: A case study on LinkedIn contacts for a professor in science

Table 1 - Summary statistics of gender

\begin{tabular}{|c|c|c|}
\hline Gender & Female & Male \\
\hline Number of networks & $210(28.0 \%)$ & $541(72.0 \%)$ \\
\hline Average percentage of female contacts in networks (\%) & $37.8 \pm 1.8 \%$ & $24.2 \pm 1.0 \%$ \\
\hline Total number of contacts in the networks & $35108(26.6 \%)$ & $97148(73.4 \%)$ \\
\hline Average number of contacts & 167 & 180 \\
\hline Saviness $(S)$ & 0.95 & 1.02 \\
\hline
\end{tabular}

networks, female networks constitute about $28.0 \%$ of the networks and have $26.6 \%$ of the sum of all the contacts, yielding a savviness value $S=0.95$. The remaining $72 \%$ male networks making up the rest of the primary user's LinkedIn network have $73.4 \%$ of the contacts such that $S=1.02$. The $S$ values are close to 1 why we conclude that there is no significant difference in networking savviness between the genders in this study. This quantitative result is similar to what have been found in other studies (Forret \& Dougherty, 2001; Sturges et al., 2002; Wanberg et al., 2000; Wolff \& Moser, 2006). In contrast, Nicholson (2011) found that men are generally more savvy networkers than women, i.e. have a larger share of the total amount of one-way contacts, at least among LinkedIn users in the U.S., from which their analysis was based. Our data is not limited to USA but biased toward Europe in general and Scandinavia in particular. It may be the case that men and women are more equally networking savvy in these regions.

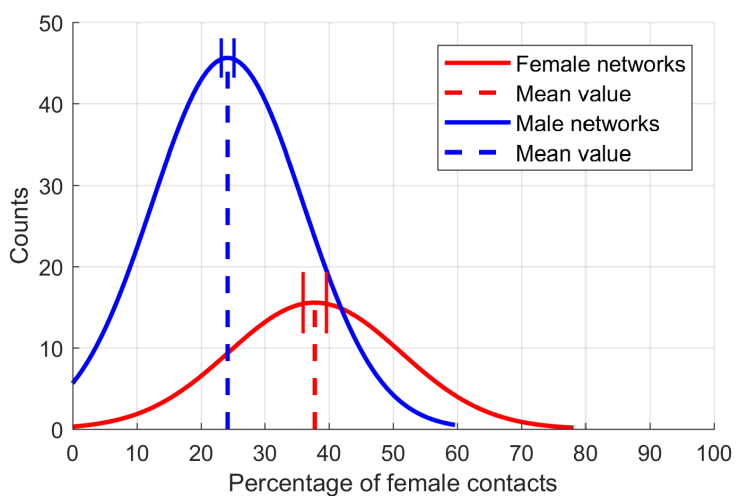

Figure 2 - Network compositions for female and male networks. Normal distribution fits to frequency plots for male (Blue; $n=541$ ) and female (red; $n=210$ ) networks versus the percentage of female contacts.
Age

Fig 3 displays the percentage of female contacts for female and male networks as a function of age. Each scatter point represents a female (red points) and male (blue points) network. The size of each point is directly proportional to the number of contact in each network. A non-weighted least square linear regression has been fitted in the scatter plots to display any trends between the number of female contacts in the LinkedIn networks and the age of network users. There exists virtually no trend between the number of female contacts in the female networks and their age, while a negative trend is indicated for male networks, i.e. the number of female contacts generally decreases with age among the male networks. Female networks are on the other hand more diverse in the distribution of network compositions: some female networks have a very high ratio of female contacts (up to $80 \%$ ) while others have very low (down to below 10\%). Male networks do not show this spread. This difference can also be spotted in the distributions in Fig 2: qualitatively, the distribution for female networks is wider than the distribution for male networks. The result indicates that older male users have less gender equal networks. Most of the networks in this dataset work within STEM (Sec. Field of work), and efforts on gender equality in i.e. STEM fields could be a reason why younger male users have more female contacts in their networks. For instance, in the U.S., the percentage of Bachelor's degrees awarded to women has risen from $16.0 \%$ to $40.2 \%$ between 1960 to 1989 (Barber, 1995). 
Professional networking by gender: A case study on LinkedIn contacts for a professor in science

Table 2 - Summary statistics of sector.

\begin{tabular}{|c|c|c|}
\hline Female networks & Public sector & Private sector \\
\hline Number of networks & $140(71.1 \%)$ & $57(28.9 \%)$ \\
\hline Average percentage of female contacts in networks (\%) & $39.1 \pm 2.3 \%$ & $35.9 \pm 3.7 \%$ \\
\hline Total number of contacts in networks & $22606(66.8 \%)$ & $11212(33.2 \%)$ \\
\hline Saviness $(S)$ & 0.94 & 1.15 \\
\hline Male networks & Public sector & Private sector \\
\hline Number of networks & $305(59.2 \%)$ & $210(40.8 \%)$ \\
\hline Average percentage of female contacts in networks (\%) & $23.7 \pm 1.33 \%$ & $22.9 \pm 1.4 \%$ \\
\hline Total number of contacts in networks & $52612(55.2 \%)$ & $42744(44.8 \%)$ \\
\hline Saviness $(S)$ & 0.93 & 1.10 \\
\hline
\end{tabular}

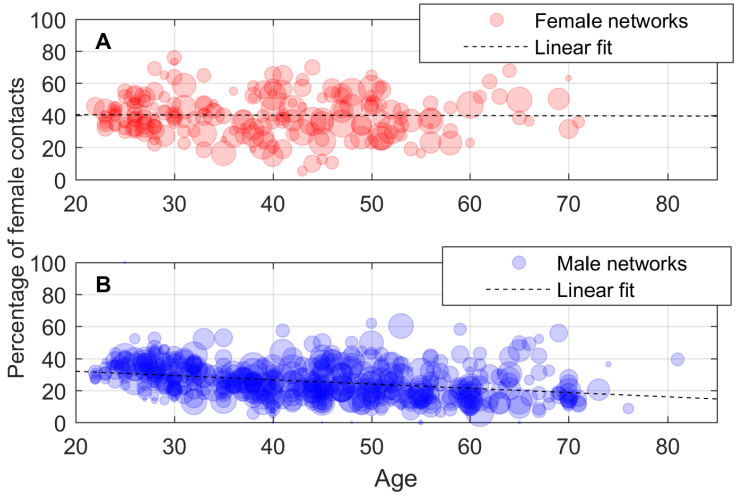

Figure 3 - Scatter plots of network composition as a function of age. Scatter plot of percentage of female contacts among networks as a function of age for (A) female networks and (B) male networks with non-weighted linear regressions. The sizes of the scatter points are proportional to the size of each network.

\section{Sector of work}

The data from Table 2 depicted in Fig 4 shows that there are more networks with users working in the public sector than private sector in our study, for female and male networks alike. This is not surprising as the starting point for our study is as a professor working in the public field himself, and his network is likely biased towards contacts in the same sector of work. Fig 4 shows that there is no significant difference in the average gender composition of the networks. However, the data in Table 2 indicates that networks within the private sectors are more networking savvy. Female networks in the private sector have a savviness score of $S=1.15$, and male networks in the private sector have a savviness score $S=1.10$. This savviness analysis demonstrates quantitative differences between groups that otherwise would not be seen in Fig 4. The results suggest that professionals in the private sector are generally more networking savvy, which could indicate that LinkedIn networking is more common in the private sector.

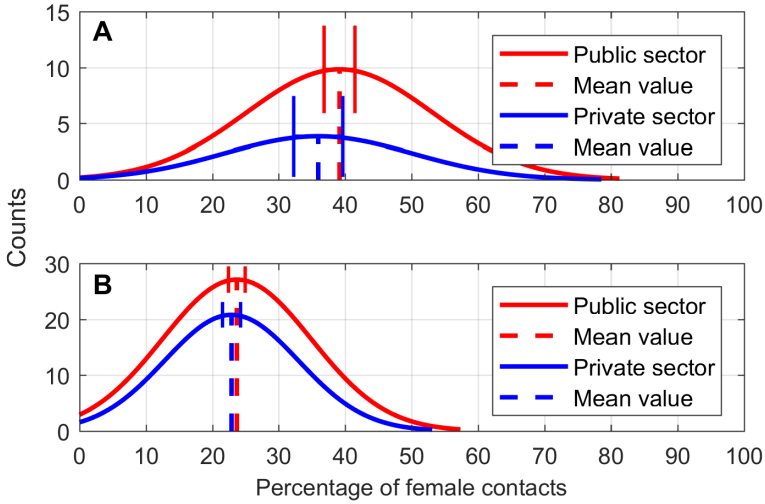

Figure 4 - Network compositions for female and male networks in private and public sectors. (A) Normal distribution fits to frequency plots for female networks $\left(n_{\text {public }}=140, n_{\text {private }}=57\right)$ divided into public (red) and private sector (blue) versus the percentage of female contacts. (B) Normal distribution fits to frequency plots for male networks $\left(n_{\text {public }}=305, n_{\text {private }}=210\right)$ divided into public (red) and private sector (blue) versus the percentage of female contacts.

\section{Field of work}

STEM networks are over-represented for both sexes (Table 3), which is expected due to the primary user in this case study being a professor in a science (STEM) field. About $58.9 \%$ and $67.8 \%$ of female and male networks work in a STEM field respectively (Table 3). The STEM 
Professional networking by gender: A case study on LinkedIn contacts for a professor in science

Table 3 - Summary statistics of field of work.

\begin{tabular}{c|c|c} 
Female networks & STEM & Other \\
\hline Number of networks & $123(58.9 \%)$ & $86(41.1 \%)$ \\
\hline Average percentage of female contacts in networks $(\%)$ & $34.7 \pm 2.0 \%$ & $42.5 \pm 3.5 \%$ \\
\hline Total number of contacts in networks & $25790(64.3 \%)$ & $14318(35.7 \%)$ \\
\hline Saviness $(S)$ & 1.09 & 0.87 \\
\hline Male networks & STEM & Other \\
\hline Number of networks & $364(67.8 \%)$ & $173(32.2 \%)$ \\
\hline Average percentage of female contacts in networks $(\%)$ & $24.1 \pm 1.7 \%$ & $25.0 \pm 1.9 \%$ \\
\hline Total number of contacts in networks & $112986(79.2 \%)$ & $29662(20.8 \%)$ \\
\hline Saviness $(S)$ & 1.17 & 0.65
\end{tabular}

field is male dominated; in the U.S, women hold only $24 \%$ of STEM jobs (Beede et al., 2011). At the same time, about $24 \%$ of all tertiary STEM graduates in the U.S. are women. This number varies greatly between countries, but the international median is $24.2 \%$ (Stoet \& Geary, 2018). The difference between men and women may be a consequence of the discriminating structures within these fields (Rosser, 2004; Schiebinger, 2008), as shown in recent research, that also seems to affect women's lower interest in STEM educations and occupations (Tellhed, Bäckström, \& Björklund, 2017). The data in Table 3 show that $25.3 \%$ of all STEM networks are female in this study, which is close to the international median of STEM graduates reported (Stoet \& Geary, 2018).

For male networks there is no significant difference in the average amount of female contacts between the groups in Fig 5. For female networks however, there is a significant difference between the two groups as Fig 5 shows (see also Table 3). Female networks working in STEM fields have on average fewer female contacts $(34.7 \%)$ than female networks working in other fields (42.5\%). Again, this may be due to the male dominance in STEM fields; there are simply fewer females available to network with. Compared to the rest of the data in the case study, female networks in non-STEM fields in fact are the most gender equal networks.

Female networks within STEM fields have a savviness score of $S=1.09$. Men in STEM fields are more networking savvy too: male networks in STEM fields score $S=1.17$. As for networks within the private sector, networking seems more widespread in STEM fields. Other research on this matter explains that employees

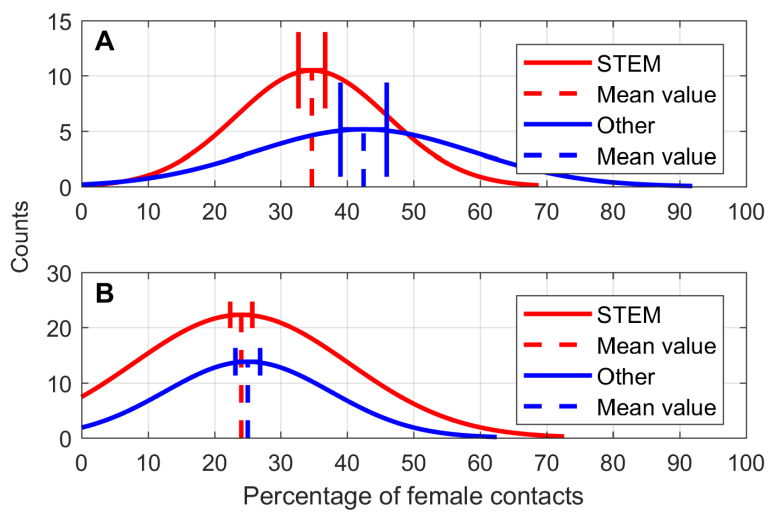

Figure 5 - Network compositions for female and male networks in STEM and other fields. (A) Normal distribution fits to frequency plots for female networks $\left(n_{\text {STEM }}=123, n_{\text {other }}=86\right)$ divided into STEM (red) and Other (blue) fields versus the percentage of female contacts. (B) Normal distribution fits to frequency plots for male networks $\left(n_{\mathrm{STEM}}=364, n_{\text {other }}=173\right)$ divided into STEM (red) and Other (blue) fields versus the percentage of female contacts.

in STEM fields are more reliant on social networking as the scientific aspect of the work very much depends on a professional network to display and access results and developments (Xu \& Martin, 2011). We note that STEM occupations could equally often be in both the private and the public sector, such as academia.

\section{Education}

The majority of all networks are $\mathrm{PhD}$ networks (Table 4), but this majority is due to the male networks. Among female networks $44.2 \%$ are PhD networks (Table 4). PhD networks generally have significantly fewer female contacts, 
Professional networking by gender: A case study on LinkedIn contacts for a professor in science

Table 4 - Summary statistics of education.

\begin{tabular}{c|c|c} 
Female networks & PhD & Other \\
\hline Number of networks & $92(44.2 \%)$ & $116(55.8 \%)$ \\
\hline Average percentage of female contacts in networks $(\%)$ & $33.1 \pm 2.5 \%$ & $41.0 \pm 2.4 \%$ \\
\hline Total number of contacts in networks & $16899(48.2 \%)$ & $18190(51.8 \%)$ \\
\hline Saviness $(S)$ & 1.09 & 0.93 \\
\hline Male networks & PhD & Other \\
\hline Number of networks & $318(60.3 \%)$ & $209(39.7 \%)$ \\
\hline Average percentage of female contacts in networks $(\%)$ & $20.9 \pm 1.1 \%$ & $27.7 \pm 1.5 \%$ \\
\hline Total number of contacts in networks & $61028(79.2 \%)$ & $36120(37.2 \%)$ \\
\hline Saviness $(S)$ & 1.04 & 0.94
\end{tabular}

indicating that workplaces with a high level of education among employees (such as universities) may be more male dominated. In Sec. Age, we found indication of a negative correlation between male networks' age and percentage of female contacts. It is conceivable that many of the male $\mathrm{PhD}$ networks are older males, which could explain this result. However, it was found that the average age among male $\mathrm{PhD}$ networks was 36 and the average age among female $\mathrm{PhD}$ networks was 34 . Moreover, the age distribution among the $\mathrm{PhD}$ networks is weighted toward lower ages (not shown), meaning that for male networks, age does not explain the difference in network gender composition for those with and without a PhD.

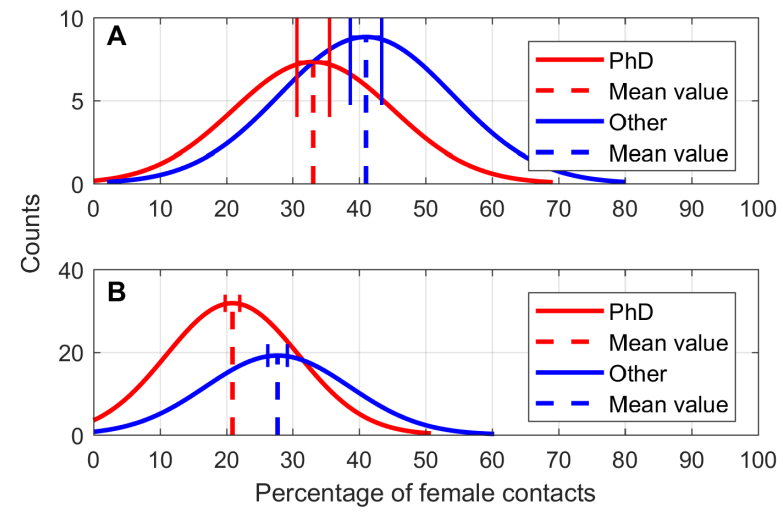

Figure 6 - Network compositions for female and male networks with and without a PhD. (A) Normal distribution fits to frequency plots for female networks $\left(n_{\mathrm{PhD}}=93, n_{\text {other }}=116\right)$ with a $\mathrm{PhD}$ (red) and without a $\mathrm{PhD}$ (blue) versus the percentage of female contacts. (B) Normal distribution fits to frequency plots for female networks $\left(n_{\mathrm{PhD}}=318, n_{\text {other }}=209\right)$ with a $\mathrm{PhD}(\mathrm{red})$ and without a $\mathrm{PhD}$ (blue) versus the percentage of female contacts.
In terms of networking savviness, female $\mathrm{PhD}$ networks have a savviness score of $S=1.09$ and are therefore determined more savvy than female non-PhD networks with $S=0.93$. Male PhD networks, however, score $S=1.04$, while male non-PhD networks score $S=0.94$. In Materials and methods we determined that two or more groups are equally networking savvy if $0.95 \leq S \leq 1.05$ for all groups. In this particular case, savviness $S$ of one of the groups falls within this range, while $S$ of the other group does not. Therefore, male $\mathrm{PhD}$ networks are considered more networking savvy. The results show that professionals with a high level of education have larger professional networks, which may be a consequence of networking with other students during the course of their studies (Forret \& Dougherty, 2001).

The result for the networks agrees with the results in Fig 5 where we found that networks in STEM occupations are generally more networking savvy. The PhD networks are also likely to work in a STEM field, due to the occupation of the primary user. At the same time, it may be contradicting with the results we found for networks in public and private sectors, i.e. that contacts in the public sector are less networking savvy. It is likely that a PhD network here is in the public sector, too. Dividing $\mathrm{PhD}$ networks into what sector they work in, we find that out of all $\mathrm{PhD}$ networks, 284 are in the public sector and 120 are in the private sector, which confirms the suspicion that many PhDs work in the public sector. In contrast, out of the non-PhD networks 147 work in the public sector and 160 work in the private sector. The results suggest that differences in networking savviness rely more on field of work (STEM or 
Professional networking by gender: A case study on LinkedIn contacts for a professor in science

Table 5 - Summary statistics of region.

\begin{tabular}{c|c|c|c} 
Region (all networks) & Scandinavia & Europe & North America \\
\hline Number of networks & $516(74.1 \%)$ & $119(17.1 \%)$ & $61(8.8 \%)$ \\
\hline Average percentage of female contacts in networks $(\%)$ & $31.2 \pm 1.1 \%$ & $19.1 \pm 1.8 \%$ & $19.4 \pm 2.2 \%$ \\
\hline Total number of contacts in networks & $90300(71.9 \%)$ & $20459(16.3 \%)$ & $14858(11.8 \%)$ \\
\hline Saviness $(S)$ & 0.97 & 0.95 & 1.34
\end{tabular}

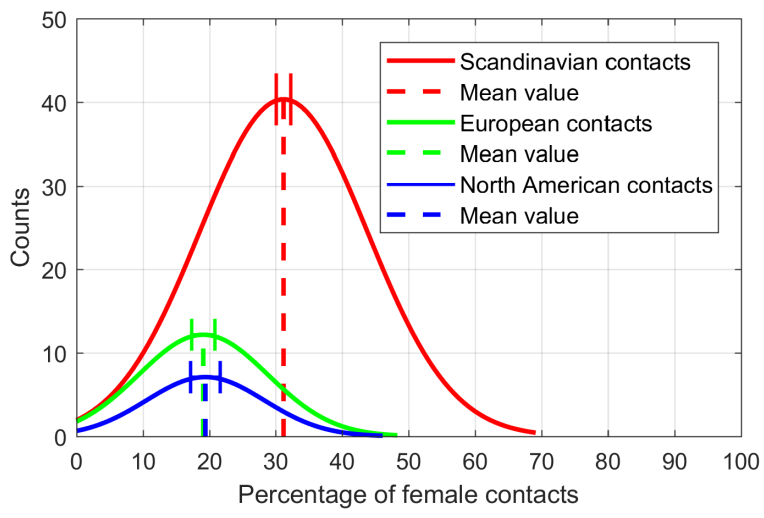

Figure 7 - Network compositions for all networks, based on region. Normal distribution fits to frequency plots for networks in Scandinavia (red; $n_{\mathrm{SC}}=516$ ), other European countries (green; $n_{\mathrm{EU}}=119$ ) and North America (blue; $n_{\mathrm{NA}}=61$ ) versus the percentage of female contacts.

other) rather than sector of work (public or private), as networks with a $\mathrm{PhD}$ here are likely to be in a STEM field in the public sector.

\section{Area of residence}

The gender compositions of LinkedIn networks were investigated after area of residence (Table 5). Science is inherently an international field and this case study is no exception: the number of countries represented among the LinkedIn networks in the study was 42 . However, the number of networks per single country was not large enough for statistical analysis. For this reason, the data is presented by categorizing only networks residing in Scandinavia (Denmark, Norway, Sweden, Finland), other European countries and North America. The results of analyzing the gender composition of these networks is displayed in Fig 7.

Scandinavian networks outnumber other European and North American networks as the primary user in this study has been living and working in Scandinavia for the last 25 years. It is interesting to note how the distribution curves differ between the regions in Fig 7. While the distributions and mean values for European and North American networks are quite similar, Scandinavian networks have significantly more female contacts on average. Note that the mean values of female contacts for other European and North American networks are lower than the average for male and female networks in Fig 2. Indeed, a stereotypical perception is that Scandinavia is more gender equal than other places (Nielsen, 2017) and, if anything, this result does not contradict that stereotype. In the Gender Gap Report 2017, the World Economic Forum (WEF) ranked the best to worst countries in gender equality. Out of the top five countries, four were Scandinavian (Schwab et al., 2017).

\section{Main outcome and conclusion}

By studying networks on an internet-based platform, we have made an attempt at studying professional networking behavior. Starting from a LinkedIn network of a white middle aged male professor in STEM, we were able to analyze 751 LinkedIn networks and make some interesting observations regarding networking between female and male LinkedIn users in the categories gender, age, sector of work, field of work, education and area of residence. By using the quantitative measure of savviness (Eq 1) we determined that STEM networks and networks in the private sector were savvier than non-STEM networks and networks in the public sector respectively, for female and male networks alike. Education was also found to be an indicator of savviness: $\mathrm{PhD}$ networks were savvier than non-PhD networks, but had generally less gender equal professional networks. 
Professional networking by gender: A case study on LinkedIn contacts for a professor in science

North American networks were savvier than Other European and Scandinavian networks, who were equally savvy. However, Scandinavian networks had about $50 \%$ more female contacts in their networks on average than North American and Other European networks.

While the female networks always had a more balanced gender composition on average than male networks, their compositions differed more: some had a high share of female contacts while other had a low share. The average percentage of female contacts was independent of age for female networks, but a negative age trend was visible in the male networks. The most gender equal networks on average were female non-STEM networks, who had an average female contact share of $42.5 \%$.

\section{Limitations and directions for fu- ture research}

Our data set is limited to the networks from contacts belonging to a single LinkedIn user, and may be biased in several ways. Hence, the results may not be transferable to replicate studies nor provide an accurate view of professional networking for the average LinkedIn user. Another limitation is the number of networks included in the study. With more and larger networks, the statistical analysis can be improved. For further studies, we suggest obtaining data from more networks from all kinds of areas and users and, if possible, categorical data from their contacts as well. It would be interesting to repeat the data collection from the networks included in this study to see if there have been developments in the statistics over time.

\section{Acknowledgements}

The authors would like to acknowledge and thank the anonymous professor in science whose LinkedIn account this study is based on for providing the data.

\section{Author disclosure statement}

The authors declare no commercial associations that could potentially lead to conflict of interests.

\section{References}

Aldrich, H. (1989). Networking among women entrepeneurs. In C. R. Oliver Hagan \& D. Sexton (Eds.), Women-owned businesses (p. 103-132). Praeger.

Allred, B. B., Snow, C. C., \& Miles, R. E. (1996). Characteristics of managerial careers in the 21st century. Academy of Management Perspectives, 10(4), 1727. Retrieved from https://doi.org/10 $.5465 /$ ame .1996 .3145316 doi: 10.5465/ ame.1996.3145316

Aslam, S. (2018). Linkedin by the numbers: Stats, demographics and fun facts. https://www.omnicoreagency .com/linkedin-statistics/.

Barber, L. A. (1995). U.s. women in science and engineering, 1960-1990: Progress toward equity? The Journal of Higher Education, 66(2), 213-234. Retrieved from http://www.jstor.org/ stable/2943912

Beede, D., Julian, T., Langdon, D., McKittrick, G., Khan, B., \& Doms, M. (2011). Women in stem: A gender gap to innovation. https://files.eric.ed.gov/ fulltext/ED523766.pdf.

Darrow, B. (2017, Apr). Linkedin claims half a billion users. Fortune.

Forret, M. L., \& Dougherty, T. W. (2001). Correlates of networking behavior for managerial and professional employees. Group 8 Organization Management, 26(3), 283-311.

Forret, M. L., \& Dougherty, T. W. (2004). Networking behaviors and career outcomes: differences for men and women? Journal of Organizational Behavior: The International Journal of Industrial, Occupational and Organizational Psychology and Behavior, 25 (3), 419-437. 
Professional networking by gender: A case study on LinkedIn contacts for a professor in science

Gould, S., \& Penley, L. E. (1984). Career strategies and salary progression: A study of their relationships in a municipal bureaucracy. Organizational Behavior and Human Performance, 34(2), 244 - 265.

Grant, S. (2017). Men vs. women social media usage. https://www.linkedin.com/ $\mathrm{pulse} / \mathrm{men}-\mathrm{vs}$-women-social-media -usage-stefanie-grant.

Heijde, C. M. V. D., \& Van Der Heijden, B. I. (2006). A competence-based and multidimensional operationalization and measurement of employability. Human Resource Management: Published in Cooperation with the School of Business Administration, The University of Michigan and in alliance with the Society of Human Resources Management, 45(3), 449-476.

King, Z. (2004). Career self-management: Its nature, causes and consequences. Journal of vocational behavior, 65(1), 112-133.

Nicholson, S. (2011). The gender divide: Are men better than women at social networking? https://blog.linkedin.com/ 2011/06/22/men-vs-women\#_ftn1.

LinkedIn Blog.

Nielsen, M. W. (2017). Scandinavian approaches to gender equality in academia: a comparative study. Scandinavian Journal of Educational Research, 61(3), 295318.

Rosser, S. V. (2004). The science glass ceiling: Academic women scientist and the struggle to succeed. New York Routledge.

Schiebinger, L. (2008). Gendered innovations in science and engineering. Stanford University Press.

Schoen, C., Rost, K., \& Seidl, D. (2018, 11). The influence of gender ratios on academic careers: Combining social networks with tokenism. PLOS ONE, 13(11), 121. Retrieved from https://doi.org/ 10.1371/journal.pone.0207337 doi: 10.1371/journal.pone.0207337

Schwab, K., Samans, R., Zahidi, S., Leopold, T. A., Ratcheva, V., Hausmann, R., \& Tyson, L. D. (2017). The global gender gap report. http://www3. weforum.org/ docs/WEF_GGGR_2017.pdf. World Economic Forum.
Stoet, G., \& Geary, D. C. (2018). The genderequality paradox in science, technology, engineering, and mathematics education. Psychological science, 29(4), 581-593.

Sturges, J., Guest, D., Conway, N., \& Davey, K. M. (2002). A longitudinal study of the relationship between career management and organizational commitment among graduates in the first ten years at work. Journal of Organizational Behavior, 23(6), 731-748. doi: 10.1002/ job.164

Tellhed, U., Bäckström, M., \& Björklund, F. (2017, Jul 01). Will i fit in and do well? the importance of social belongingness and self-efficacy for explaining gender differences in interest in stem and heed majors. Sex Roles, 77(1), 86-96. doi: 10.1007/s11199-016-0694-y

van den Brink, M., \& Benschop, Y. (2014). Gender in academic networking: The role of gatekeepers in professorial recruitment. Journal of Management Studies, 51(3), 460-492. doi: 10.1111/joms.12060

Wanberg, C. R., Kanfer, R., \& Banas, J. T. (2000). Predictors and outcomes of networking intensity among unemployed job seekers. Journal of Applied Psychology, $85(4), 491$.

Wolff, H.-G., \& Moser, K. (2006). Entwicklung und validierung einer networkingskala. [development and validation of a networking scale.]. Diagnostica, 52(4), 161-180. doi: 10.1026/0012-1924.52.4.161

Xu, Y. J., \& Martin, C. L. (2011). Gender differences in stem disciplines: From the aspects of informal professional networking and faculty career development. Gender Issues, 28(3), 134.

Yang, Y., Chawla, N. V., \& Uzzi, B. (2019). A network's gender composition and communication pattern predict women's leadership success. Proceedings of the National Academy of Sciences, 116(6), 2033-2038. 


\section{Supporting information}

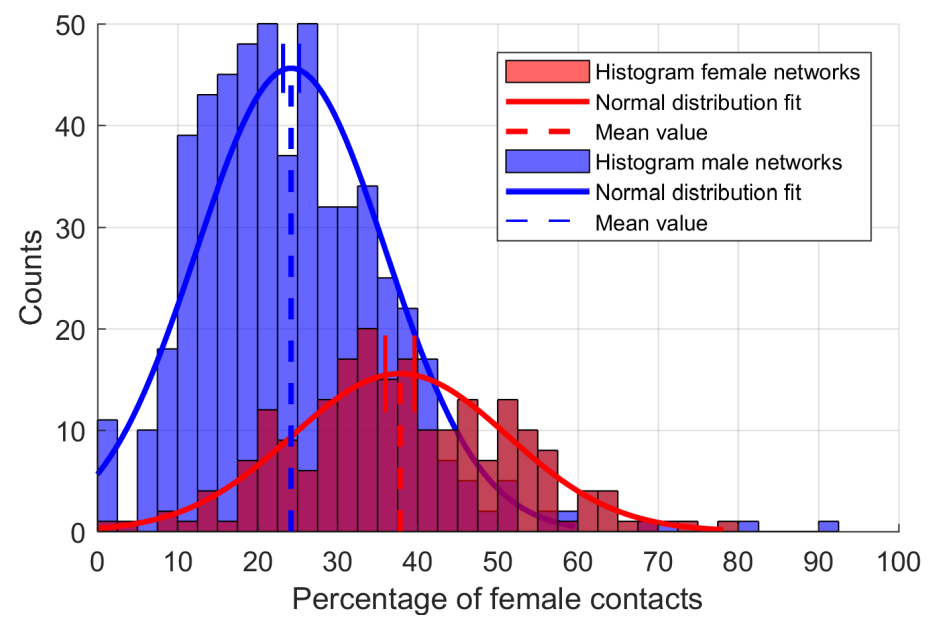

Figure S1 - Frequency plots of female and male networks with normal distribution fits versus the percentage of female contacts.

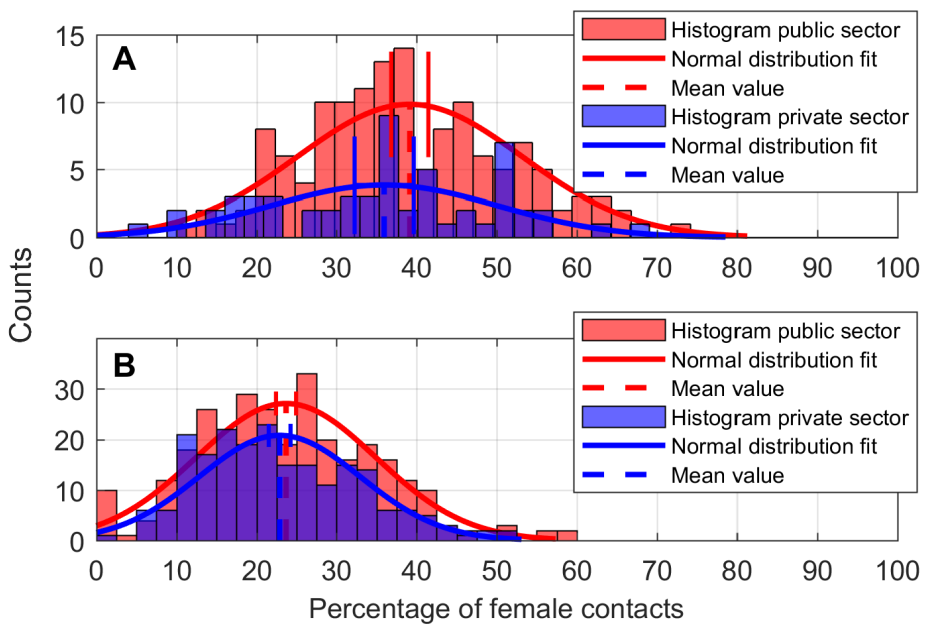

Figure S2 - Frequency plots of female and male networks in private and public sectors with normal distribution fits versus the percentage of female contacts. 


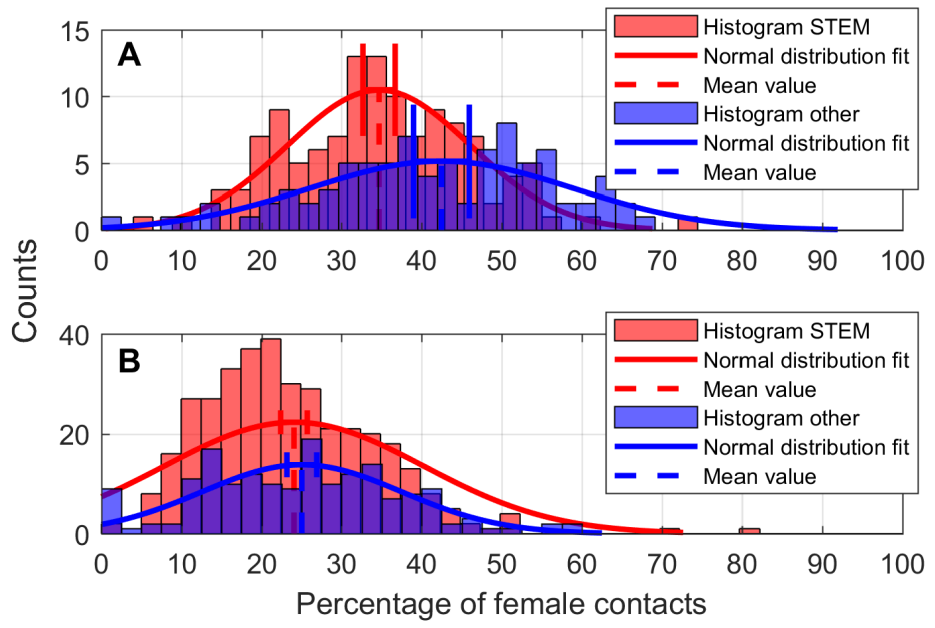

Figure S3 - Frequency plots of female and male networks working in STEM and other fields with normal distribution fits versus the percentage of female contacts.

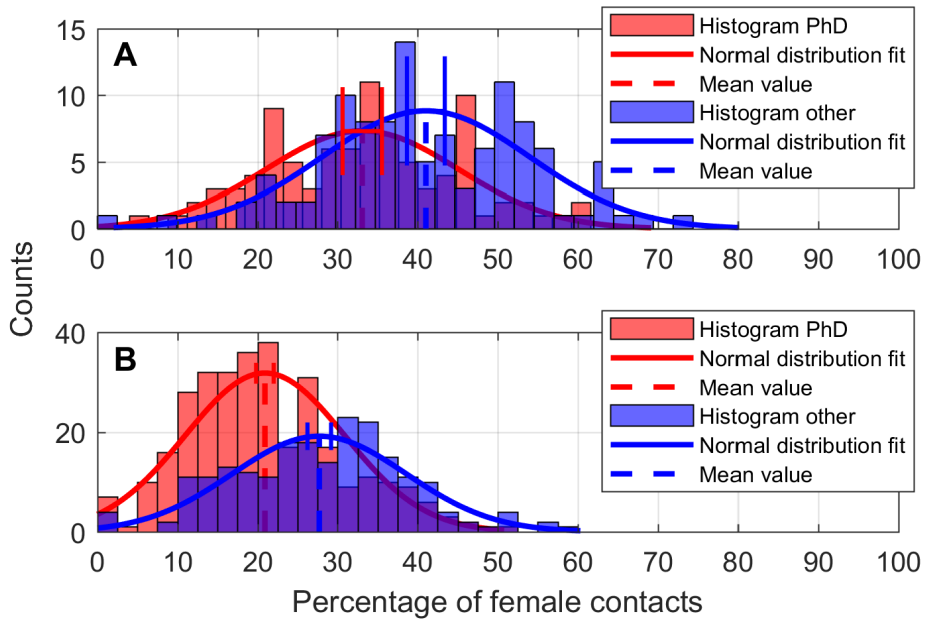

Figure S4 - Frequency plots of female and male networks with and without a PhD degree with normal distribution fits versus the percentage of female contacts. 


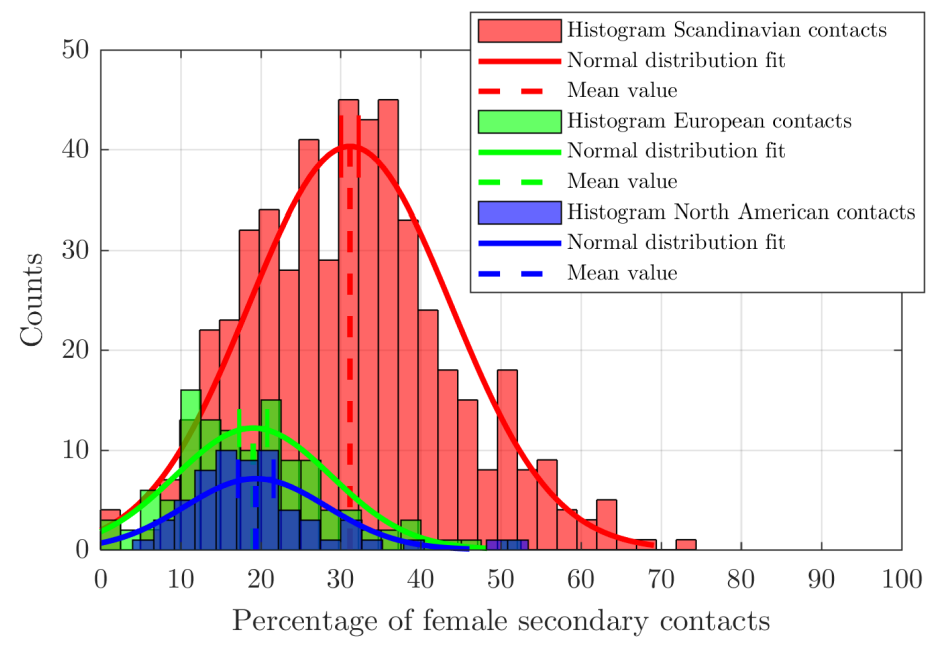

Figure S5 - Frequency plots of all networks in Scandinavia, Europe and North America with normal distribution fits versus the percentage of female contacts. 
Professional networking by gender: A case study on LinkedIn contacts for a professor in science

\section{Appendix - Summary of the attempts to publish this manuscript in pro- fessional journals}

\section{8-Mar-18 Manuscript submitted to PLOS ONE \\ 2018-Mar-28 Rejection by PLOS ONE}

PONE-D-18-08889 Professional networking by gender: A case study on LinkedIn contacts for a professor in science

Dear Dr. Deppert,

Thank you very much for submitting your manuscript to PLOS ONE. After careful consideration, we have decided that your manuscript does not meet our publication criteria and thus, cannot be considered further for publication.

We felt that the scientific contributions of the research needed to be further explicated, were concerned that the behavior of a single user's network would not be generalizable to other networks, and that competing explanations for the observed patterns, as one example, gender bias in the marketing and advertisement activities of/on LinkedIn, could not be ruled out.

In addition, for all studies using personal data from internet-based and other third-party sources, authors must specify that the data was collected and used according to company/website Terms and Conditions and with appropriate permissions and declare any potential risks to individuals or individual privacy, or affirm that in their assessment, the study posed no such risks. Further, if authors accessed any personal identifying information, an Ethics or Data Protection Committee should oversee data anonymization.

I am sorry that we cannot be more positive on this occasion, but hope that you understand the reasons for this decision.

All best wishes, Deanne Dunbar, PhD Associate Editor, PLOS ONE

\section{8-Jul-17 Manuscript re-submitted to PLOS ONE}

\section{8-Jul-16 Rejection by PLOS ONE}

PONE-D-18-21002 Professional Networking by Gender: A Study of 751 LinkedIn Networks

Dear Dr. Deppert,

Thank you for resubmitting your manuscript for review by PLOS ONE. After careful consideration, we have decided that your manuscript does not meet our publication criteria and must therefore be rejected.

This manuscript is a resubmission of PLOS ONE submission PONE-D-18-08889, which was previously rejected prior to peer review. Specifically, for all studies using personal data from internetbased and other third-party sources, authors must specify that the data was collected and used according to company/website Terms and Conditions and with appropriate permissions and declare any potential risks to individuals or individual privacy, or affirm that in their assessment, the study posed no such risks. Further, if authors accessed any personal identifying information, an Ethics or Data Protection Committee should oversee data anonymization. Unfortunately, we do not feel that these concerns have been sufficiently addressed.

In the light of the remaining concerns, we feel that the manuscript does not currently meet our requirements for submissions analyzing third party-data (http://journals.plos.org/plosone/ s/submission-guidelines\#loc-personal-data-from-third-party-sources). 
Professional networking by gender: A case study on LinkedIn contacts for a professor in science

I am sorry that we cannot be more positive on this occasion, but hope that you understand the reasons for this decision.

All best wishes, Deanne Dunbar, PhD Associate Editor, PLOS ONE

2019-Sep-04 Manuscript submitted to Journal of Gender Studies

2019-Mar-02 Request for revision by Journal of Gender Studies

Dear Knut Deppert:

Your manuscript entitled "Professional networking by gender: A case study on LinkedIn contacts for a professor in science", which you submitted to Journal of Gender Studies, has been reviewed.

The reviewer(s) would like to see revisions made to your manuscript before we consider it. Therefore, I invite you to consider the reviewer(s)' comments before making a decision on whether you wish to undertake changes. These comments appear at the end of this email. Since the revisions are substantial it would be helpful if you could let us know whether you intend to pursue the paper or wish to withdraw it within three months.

Once again, thank you for submitting your manuscript to Journal of Gender Studies and I look forward to receiving your revision.

Sincerely, Dr Hall Editor in Chief, Journal of Gender Studies mhall@arden.ac.uk

Reviewers comments combined:

1. The abstract briefly detailing the aim and the scope of the paper along with the description of the research work that is done in the paper can be included to the paper. A motivating abstract often starts with the phrase 'This study presents ...' or 'In this study, we present 2 . The motivation behind the study and the organization of the study can be included below the introduction. 3 . The materials and the methods used can be explained in a detailed manner. 4. Include adequate figures representation supporting the materials and the methods used. 5. Include the outcomes of the case study to the paper. 6. Include a conclusion to the paper that provides the summary of the work done in the paper along with its future enhancements. 7. Update and complete the references by including more recent papers and numbering them sequentially. The reference papers are to be cited into the body of the paper

\section{9-Nov-06 Revised manuscript submitted to Journal of Gender Studies 2020-Jun-23 Rejection by Journal of Gender Studies}

Dear Dr Deppert,

I regret to inform you that our reviewers have now considered your paper but unfortunately feel it unsuitable for publication in Journal of Gender Studies. For your information I attach the comments at the bottom of this email. I hope you will find them to be constructive and helpful. You are of course now free to submit the paper elsewhere should you choose to do so.

There is a high demand for publication through the Journal of Gender Studies and often we have to make difficult decisions about which articles to support through to completion so I hope the outcome of this specific submission will not discourage you from the submission of future manuscripts and we wish you good luck in future research projects.

Thank you for considering Journal of Gender Studies.

Sincerely, Dr Hall Editor, Journal of Gender Studies mhall@arden.ac.uk 
Professional networking by gender: A case study on LinkedIn contacts for a professor in science

Reviewer comments:

The paper aims to understand gender differences in an attribute termed "work savviness" and uses work contacts in LinkedIn network to describe common trends involving gender ratios.

On the plus side, the author uses a novel method to understand social or networking skills across sectors. However, the biggest challenge of the method might be partial out the effect of a single user being used for deriving theoretical insights about work savviness. The choice of this user, its gender, disposition, work setting parameters will influence his network. Ideally, the author should at the least, find a similar profile female researcher and carry out similar comparison. Maybe then the insights obtained will be able to help us understand potential differences that the author highlights in this work.

At this point, the present approach is severely limited in drawing meaningful conclusions. The problem is further compounded by the fact that most of the insights that the author reports are reasonably intuitive (public vs. private, STEM vs non-STEM).

More importantly, one of the main idea of quantifying network savviness seems to be quite weak in its conceptualization. The author state "the study, the team defined "networking savvy" as the ratio of one way contacts for female and male contacts to the percentage of female and male contacts in a number of professional occupations. For example, a given profession was said to be female savvy if $30 \%$ of the contacts in the profession (category) were female but had $60 \%$ of all one way contacts in that profession or category." Though it is important to devise this metric, it will require slightly more detailed explanation. For instance, LinkedIn provides suggestions for contact which we are not aware, but will be different for different users, and are probably derived from a combination of metrics about the user's profile (education, alma mater network, employer network, skill-training, place of stay etc). The extent to which a nature of network contacts (measure of S) reflects a user's agency, or own actions versus AI-derived prompts that the user blindly "accepts" is missing, time spent engaging in the site might further differ between males and females, greater time spent will increase ration of contacts made - the paper should through light on these and similar issues while quantifying the construct.

Further, it might have been important to understand how networking savviness impacts careers, we encourage the authors to document some aspects of how this measure impacts career progression of men and women. It will also help the readers understand the larger and potential implications of this work.

In summary, the idea that males and females differ in networking savviness is intuitive but still interesting, careful documenting of this phenomenon will be beneficial, however, in its present form, the paper takes up this task rather casually.

\section{0-Jun-25 Comments by the authors on handling the manuscript by Journal of Gender Studies}

1. The handling process by the journal was extremely lengthy. It took six months for the first review process and six and a half months for the second review process. For a journal that would like to publish timely research, this is unacceptable.

2. While the first reviewing comments were rather strange comments, the comments from the reviewer in the second round were more profound. However, they were of a complete different type and contained complete different requests than the comments that led to a revision.

3. While the comments by the reviewer in the second round were rather profound, the request that "the author should at the least, find a similar profile female researcher and carry out similar comparison" can only be judged as a non-achievable wish. On one hand, the single study carried 
Professional networking by gender: A case study on LinkedIn contacts for a professor in science

out by us needed to handle already a huge data amount and on the other hand, the reviewer may than argue that we need to complement with data starting from persons of other age, other profession, other countries, etc. Additionally, our research exhibits a snapshot in time. With the long review process, we have no chance of making a similar snapshot for any other starting person at that time slot.

4. Regarding the comments by the reviewer that most results are "reasonably intuitive", we argue that we deliver facts that can thus be used to support such intuitive feelings.

5. Regarding the comments by the reviewer on the savviness, we are willing to improve our manuscript.

\section{0-Jun-26 Reply from Journal of Gender Studies}

Dear Professor Knut Deppert,

Thank you for your email.

I realise the rejection of your manuscript was likely to be disappointing. Because of the large number of submissions to the journal only around $10 \%$ of submissions are published. Whilst we would ideally like the turnarond time for reviews to be a much speedier process it can often take time to find suitable reveiwers as was the case for your paper. I appreciate you disagree with the reviewers' comments but as editors of the journal we must take a view based on the reveiwers who are specialists in that specific area of gender studies. Unfortunately, on this occassion they did not feel your paper was suitble for publication. You are therefore, free to submit to another journal.

I hope this experience will not discourage you from submitting to the journal in future.

Kind regards, Matthew

P.S. I have copied the Editor in Chief for reasons of transparency. 